\title{
O Serviço Social nas empresas frente às tecnologias da informação e comunicação
}

\author{
Monica de Jesus Cesar ${ }^{1}$ \\ https://orcid.org/0000-0002-3395-5087 \\ ${ }^{1}$ Universidade do Estado do Rio de Janeiro, Faculdade de Serviço Social, Departamento de Fundamentos Teórico-Práticos \\ do Serviço Social, Rio de Janeiro, RJ, Brasil
}

\section{O Serviço Social nas empresas frente às tecnologias da informação e comunicação}

Resumo: Este artigo tem como objeto o trabalho do assistente social nas empresas, tendo em vista as transformações operadas pela reestruturação da produção e dos processos de trabalho com a adoção de inovações organizacionais e tecnológicas. Com base na revisão da literatura e no conhecimento obtido através de experiências profissionais, sistematizações e investigações, as inferências assinalam que as mudanças nas empresas, em particular, com a expansão das tecnologias da informação e comunicação, conferem outra feição ao trabalho do assistente social, bem como modificam os requisitos do perfil profissional e as condições de trabalho.

Palavras-chave: Serviço Social; Empresas; Tecnologias da Informação e Comunicação.

\section{Social Work in companies facing information and communication technologies}

Abstract: This article has as its object the work of the social worker in companies, in view of the transformations brought about by the restructuring of production and work processes with the adoption of organizational and technological innovations. Based on the literature review and on the knowledge obtained through professional experiences, systematizations and investigations, the inferences indicate that changes in companies, in particular, with the expansion of information and communication technologies, give another aspect to the work of social workers, as well as modify the requirements of the professional profile and the working conditions.

Keywords: Social Work; Companies; Information and Communication Technologies.

Recebido em: 18.06.2021. Aprovado em: 31.08.2021. Revisado em: 16.09.2021.

\section{Introdução}

Este texto aborda o trabalho do assistente social nas empresas, considerando as transformações operadas pela reestruturação da produção e dos processos de trabalho, com a adoção das tecnologias da informação e comunicação (TIC) associadas a uma série de inovações organizacionais, verificadas no Brasil, principalmente, a partir dos anos 1990 e 2000. Estas transformações se referem às estratégias usadas 
para a redefinição da acumulação do capital, configurando o atual padrão flexível que, em oposição à suposta rigidez do fordismo, foi desencadeado para responder à crise estrutural do capital, expressa internacionalmente, a partir dos anos de 1970 e sucedida por várias outras crises inerentes a este modo de produção.

O padrão de acumulação flexível, conjugado às políticas neoliberais, tem promovido, dentre outros movimentos, a centralidade da financeirização da economia, o aprofundamento da concentração e descentralização de capitais, a desterritorialização da produção, a desregulamentação dos mercados, a retração do mercado de trabalho e a supressão dos direitos sociais e trabalhistas, atingindo os trabalhadores e suas conquistas históricas.

Na moderna empresa flexível, há profundas mudanças com a introdução de novas formas de organização da produção e gerenciamento do trabalho, com base em avanços tecnológicos e processos informacionais. Gestão da qualidade, sistema toyotista, fabricação just in time, manufatura assistida por computador, máquinas de comando numérico, informatização, automação, robótica, telemática, células de produção, trabalho em equipes, polivalência, multifuncionalidade e terceirização, ilustram essas mudanças, aprofundadas pelos recursos informacionais-digitais que moldam, atualmente, a denominada indústria 4.0.

Tais inovações colocaram novas exigências de qualificação profissional, ao mesmo tempo em que precarizaram as condições de trabalho pela intensificação do ritmo de execução das tarefas e pela articulação de mecanismos poupadores de mão-de-obra, acarretando a eliminação de postos e ocupações, bem como o aumento do desemprego. Estas mudanças inflexionaram o modo de trabalhar, o perfil do trabalhador e as condições de trabalho, rebatendo sobre a subjetividade operária, capturada nas suas dimensões cognitiva e comportamental.

Neste artigo, consideramos que as TIC expressam o desenvolvimento das forças produtivas e configuram um produto histórico resultante do trabalho e saber acumulados pela sociedade. Porém, se tornam objeto da apropriação privada pelos capitalistas, para ampliar a valorização do seu capital e aumentar a subjugação do trabalho. Sua aplicação pela empresa flexível e enxuta diminui o trabalho vivo, concentrando maior volume de trabalho morto, a fim de gerar maiores índices de produtividade e lucratividade na concorrência intercapitalista.

Longe de pretender aprofundar o conjunto das transformações mencionadas, este texto se volta para o trabalho do assistente social nas empresas, tendo em vista as inflexões produzidas pelas alterações na produção e nos processos de trabalho com a aplicação das TIC. As formulações tecidas são resultado das observações feitas através da experiência profissional em empresas e do esforço de sua sistematização e, também, da investigação sobre as inflexões do processo de restruturação sobre o trabalho do assistente social nas corporações capitalistas.

Com base na revisão da literatura e no conhecimento acumulado, as inferências assinalam, primeiramente, que as mudanças organizacionais e tecnológicas na produção, com o suporte das TIC, estão conferindo outra feição ao exercício profissional nas empresas. Em segundo lugar, indicam que estas mudanças modificam o perfil profissional e as condições de trabalho sob as quais este exercício se efetiva. Portanto, a perspectiva adotada considera a análise do trabalho e das condições de trabalho como dimensões interdependentes e articuladas.

\section{O Serviço Social nas empresas e as tecnologias da informação e comunicação}

A institucionalização do Serviço Social, nas empresas, está relacionada com os níveis de eficiência, racionalidade e produtividade exigidos pela modernização capitalista. $\mathrm{O}$ desenvolvimento das forças produtivas e as necessidades de domínio sobre a força de trabalho instauraram práticas profissionais para as funções de apoio à administração do trabalho, atuando na contenção dos conflitos e na integração dos trabalhadores às exigências da produção.

Com o crescimento industrial ocorrido no Brasil, principalmente com o ciclo autocrático burguês no pós-1964, o Serviço Social foi mobilizado pelas empresas para atenuar as tensões oriundas da exploração e da resistência dos trabalhadores, tendo em vista as necessidades de vigilância e controle da força de trabalho. $\mathrm{O}$ assistente social foi requisitado para responder às necessidades de reprodução da força de trabalho e ao controle da convivência entre patrões e empregados, buscando adaptar os trabalhadores aos ritmos do desenvolvimento capitalista. Assim, sua inserção nas empresas é "expressão de uma prática contraditória onde é possível problematizar as demandas institucionais, transformando-as em objeto da ação profissional e parte da sua política institucional" (AMARAL; CESAR, 2008, p. 154). 
A compreensão do Serviço Social, inserido na divisão social e técnica do trabalho, como um tipo de especialização do trabalho coletivo permite conceber que o desenvolvimento das forças produtivas determina a funcionalidade da profissão no enfrentamento da questão social. Consequentemente, prescreve formas de intervenção profissional na realidade, articulando suas dimensões teórica, política, ética, técnica, pedagógica e intelectual. Essa relação se evidencia quando as empresas problematizam determinadas necessidades sociais como fenômenos passíveis de intervenção, "e a profissão, para respondê-las, peculiariza um conjunto de ações reconhecidas como adequadas ao tratamento dos fenômenos" (MOTA, 2008, p. 41).

Nas empresas, o profissional encampou a execução de serviços sociais para suprir necessidades e problemas, que interferem nos processos de trabalho, através de estratégias integrativas que dão suporte à ampliação da produtividade. Com base na atividade assistencial, reforçou a mútua "colaboração" entre capital e trabalho e o enquadramento nas relações sociais vigentes. Deste modo, assumiu uma função típica do capitalista que foi delegada "a seus quadros técnicos administrativos: a de controle e disciplinamento dos operários, tendo em vista sua subordinação aos requisitos do processo de valorização" (IAMAMOTO, 1995, p. 46).

Sua funcionalidade, portanto, sempre esteve imbricada no controle da força de trabalho, intervindo sobre a vida do trabalhador dentro e fora da empresa, porém, sendo plasmada por contradições e tensionada pela luta de classes. As práticas de integração são questionadas pelos trabalhadores e seus sindicatos, levando o assistente social a se posicionar criticamente e a defender as demandas do trabalho, ainda que de modo subordinado. Aqui repousam as possibilidades de sua intervenção, "traduzidas na sua capacidade de compreender a realidade, propor alternativas e negociar, junto às direções empresariais, $\mathrm{o}$ atendimento de necessidades fundamentais à reprodução da força de trabalho" (AMARAL; CESAR, 2009, p. 415).

A intervenção do assistente social ocorre, em geral, atrelada às políticas de Recursos Humanos (RH) que, com a reestruturação das empresas, adquiriram outra racionalidade técnica e ideopolítica na chamada gestão de pessoas. Essa racionalidade gera mudanças no controle e gerenciamento da força de trabalho, que visam integrar os trabalhadores aos novos requisitos da produção, numa lógica mais consensual e menos despótica. Assim, "cabe ao Serviço Social colaborar pedagogicamente na socialização de valores e comportamentos, que deságuem na integração dos trabalhados às novas exigências de produtividade" (CESAR, 1998, p. 124).

Com a reestruturação produtiva, as novas formas sociais e técnicas de organização da produção e do processo de trabalho transformaram seus mecanismos de controle e gestão. Foi introduzida outra política e cultura do trabalho com base na negociação cooperativa, que busca "a formação de metas e propósitos que expressem consenso entre empregados e empregadores, garantindo uma relativa coesão no processo de produção" (CESAR, 1998, p. 125). Neste prisma, constata-se um conjunto de iniciativas do capital que mobilizam novos meios de consumo, modos de controle e mecanismos de reprodução material e espiritual da força de trabalho, mediados por mudanças nos processos de trabalho e nos sistemas gerenciais.

Com relação aos meios de consumo e controle da força de trabalho, as empresas introduzem a microeletrônica, ampliam a automação e a informatização do processo produtivo, com novos requisitos de capacitação e treinamento, introduzindo a polivalência e a multifuncionalidade. Sofisticam as formas de adequação do comportamento produtivo aos métodos de trabalho, através da adesão do trabalhador às metas de qualidade e produtividade. Estimulam esta adesão através dos programas participativos e incentivos materiais e simbólicos, atrelados à avaliação meritocrática do desempenho e à obtenção de resultados, esvaziando o conteúdo político das reivindicações dos trabalhadores e o poder dos sindicatos.

Quanto aos mecanismos de reprodução material e espiritual da força de trabalho, as empresas oferecem um rol de benefícios sociais, reforçando a dependência dos trabalhadores e intensificando sua subordinação à disciplina fabril. Investem num processo de aculturamento dos empregados com base no comprometimento com os objetivos empresariais. Deste modo, o discurso e as práticas gerenciais propagam o colaboracionismo entre as classes e o engajamento dos "colaboradores", aprofundando a alienação e o estranhamento (AMARAL; CESAR, 2009, p. 417-418).

De fato, as inovações tecnológicas têm resultado no desenvolvimento acelerado da geração, processamento e difusão de informações, tornando-o um elemento constitutivo dos processos de trabalho. Estas mudanças conferem uma dimensão mais qualificada ao trabalho e exigem cooperação e engajamento do trabalhador com as metas corporativas. Incitam, assim, o exercício de uma subjetividade sem autonomia e pró-parceria com o patronato, "que é sempre conformada pelos interesses das empresas, não comportando nenhum traço que confronte com o ideário do lucro e do aumento da produtividade" (ANTUNES, 2011, p. 127). 
O trabalhador massificado e especializado por tarefa da fase fordista/taylorista é substituído pela figura do "colaborador" com capacidade de interpretar e decodificar novos símbolos, interagir com pessoas e tecnologias, e antever respostas aos desafios do seu trabalho. Com base na polivalência e multifuncionalidade, o trabalhador precisa desenvolver várias habilidades para dominar diferentes atividades de um mesmo processo/ área. O trabalho passa a abranger "as atividades de controle, supervisão, de operação de equipamentos, de gestão de informações e, ocasionalmente, de interação com o cliente" (LINHART, 2007, p. 114).

A dominação capitalista do progresso técnico e a organização social do trabalho a ele associada, possibilitou diminuir o tempo de trabalho e acelerar o giro de capital. O uso das TIC propiciou maior integração das etapas do processo produtivo, redução das porosidades, dos tempos ociosos, refugos, estoques e espaços físicos, além da suposta melhoria da qualidade em contradição com a obsolescência programada de bens e produtos. Permitiu, assim, eliminar postos de trabalho e introduzir a subcontratação, ampliando a fragmentação entre os trabalhadores e enfraquecendo seus vínculos de solidariedade. De um lado, o trabalhador "informacionaldigital, capaz de exercitar com mais intensidade sua dimensão mais intelectual. De outro lado, uma massa de trabalhadores precarizados, terceirizados, flexibilizados, informalizados, cada vez mais próximos do desemprego estrutural" (ANTUNES, 2011, p. 127).

Neste contexto, o Serviço Social sofre as refrações das mudanças empreendidas na gestão empresarial, mediadas, em grande medida, pelas novas estratégias de RH. Em síntese, tais estratégias estão pautadas no gerenciamento participativo, no monitoramento do ambiente interno e na conjugação dos sistemas de benefícios, incentivos à produtividade, capacitação e treinamento. Nesse caso, o assistente social tem seu trabalho inflexionado por essas estratégias, como também sofre injunções devido à sua condição de trabalhador assalariado.

Sob esta ótica, as requisições históricas feitas pelas empresas ao Serviço Social, relativas ao disciplinamento da força de trabalho, são reeditadas, ao mesmo tempo em que o trabalho profissional é dotado de novos conteúdos e as condições para sua realização se modificam. Deste modo, as demandas do assistente social são transpassadas "por novas formas de controle da força de trabalho, exigindo a formulação de estratégias de atuação que se definem, também, em função das condições de trabalho dos profissionais" (CESAR, 1998, p. 116). De fato, como será visto a seguir, as modificações relativas à introdução das TIC no trabalho do assistente social incidem em seu conteúdo e inflexionam as condições em que este se realiza.

\section{As tecnologias da informação e comunicação no trabalho do assistente social}

Derivadas das TI, as TIC estão cada vez mais presentes nos circuitos de inovação das empresas e, para ambas, convergem a compreensão, o processamento, o tratamento, o armazenamento e a pesquisa da informação. Confluem também o acompanhamento das ferramentas e sistemas associados através do recurso à informação e, ainda, a automatização da comunicação da informação. Essa convergência tecnológica é "uma característica que está na base da definição de tecnologias da informação - compreendida como a associação, sob a base microeletrônica, da computação, informática e telecomunicações" (MELO, 2007, p. 25).

Com as TIC, é possível controlar a produção e o trabalho, conectar equipamentos, pessoas e funções dentro das empresas e entre elas, permitindo o estabelecimento das redes de comunicação e favorecendo os negócios. As TIC correspondem aos recursos tecnológicos que, integrados, viabilizam os processos informacionais e comunicativos e propiciam, através de um conjunto de objetos (hardware) e veículos (software), o processamento das informações e a comunicação. Assim, computação e telecomunicações se tornam mutuamente essenciais e interdependentes.

De fato, as inovações não se limitam ao potencial da microeletrônica nem à estocagem e circulação de informações codificadas pelos programas computadorizados ou difundidas pela mídia. As inovações compreendem, sobretudo, a criação, o acesso e a intervenção sobre informações estratégicas de natureza econômica, política, científica etc. Trata-se de uma interconexão de "informações sobre a informação, que regulam o sentido das informações operatórias, particulares, que cobrem a nossa vida cotidiana" (LOJKINE, 1995, p. 109).

$\mathrm{O}$ avanço acelerado das TIC, atualmente, adquire papel crucial entre os distintos mecanismos de acumulação criados pelo capitalismo financeiro, dando suporte a várias estratégias de gestão que vêm sendo desenvolvidas em diversos setores econômicos. A expansão das TIC viabiliza, inclusive, a denominada 
indústria 4.0, que corresponde a um novo "salto tecnológico no mundo produtivo", com a ampliação dos processos automatizados e robotizados em toda a cadeia de valor, colocando toda a logística empresarial "sob o comando informacional-digital". Sua incidência no mundo produtivo, contudo, está longe de representar o fim da centralidade do trabalho e/ou da teoria do valor, mas tem como sua contraface a "ampliação do trabalho precário", sob variadas modalidades (ANTUNES, 2020, p. 13-14).

Nas empresas, o fluxo e o tratamento da informação e da comunicação se tornaram indispensáveis à produção, permitindo integrar áreas e operações, através de sistemas interligados, com alto grau de envolvimento dos trabalhadores em seu manuseio, ainda que parcelas da força de trabalho sejam descartadas e substituídas pelo trabalho morto. Neste processo contraditório, ao mesmo tempo em que se elimina "uma quantidade incalculável da força de trabalho" pelo desemprego e/ou pelas ocupações intermitentes, também são mobilizadas novas especialidades e atividades que requerem, segundo o ideário empresarial, "mais 'aptidões', mais 'inteligência', mais "capacitações"' (ANTUNES, 2020, p. 14-15).

No contexto empresarial em que há, cada vez mais, a ampliação do uso das TIC, ocorrem duas modificações importantes no trabalho do assistente social: o redimensionamento do uso da informação e a introdução da racionalidade técnica pautada no binômio eficácia/eficiência. A primeira, referente ao redimensionamento do uso da informação, ocorre com a crescente dinamização das redes e sistemas informatizados nas empresas. Por meio desses recursos, as informações produzidas pelo Serviço Social, passam a ser utilizadas, pelas gerências, para definição de itens de controle e verificação no gerenciamento do trabalho, integrados ao planejamento global da empresa. Isto não significa, entretanto, que o profissional passe a participar da definição de diretrizes e políticas de gestão da força de trabalho, mantendo-se, então, a sua subalternidade.

Ao atender a um trabalhador, por exemplo, o assistente social realiza um conjunto de procedimentos e, através do sistema de redes, registra informações relativas à solicitação do empregado, repassa a solicitação para análise das instâncias superiores e monitora o resultado. Mesmo emitindo parecer técnico, a ação profissional tem uma autonomia limitada, pois está condicionada à decisão das gerências/diretorias. Neste caso, o uso da informação está atrelado à estrutura hierárquica, que separa os que decidem dos que se encarregam do trabalho de base, reforçando a distância entre a concepção e a execução nos processos de trabalho.

Este novo uso das informações impõe a necessidade de uma reorganização e racionalização dos serviços internos, alterando substancialmente o trabalho do assistente social. Nesse caso, o recurso tecnológico constitui "um elemento potencializador do trabalho em três aspectos principais: agilização do trabalho e dinamização do atendimento; organização e tratamento de dados; e uso de redes e da internet" (VELOSO, 2011, p. 80). Em contrapartida, tais processos também promovem uma maior racionalização, padronização e/ou rotinização do trabalho, afastando as atividades profissionais de seus conteúdos tácitos e enriquecedores.

Com maior volume de informações veiculadas nos sistemas informatizados e canais de comunicação online, o profissional deixa de trabalhar com material impresso, pois basta digitar a matrícula do empregado no terminal, por exemplo, para acessar suas informações cadastrais. Além disso, toda a comunicação passou a ser feita por mensagens no correio eletrônico, ou seja, pela intranet, estabelecendo uma maior relação com signos e símbolos expressos na tela do computador, o que implica maior abstração e capacidade cognitiva. Há, portanto, a ampliação do uso e manejo de "sistemas de comunicação e intranet, dando agilidade aos registros de ocorrências e iniciativas que têm incidência no cotidiano de trabalho dos empregados e no assessoramento das decisões das gerências e chefias" (MOTA, 2008, p. 20).

Os sistemas integrados de RH implicam a informatização do trabalho do assistente social e a adaptabilidade ao maquinário informacional-digital para estabelecer a interface com a tecnologia e a informação, exigindo maior capacitação técnica e impessoalidade. Isso significa que "o processo de trabalho já não ocorre através do insumo básico utilizado, até então em fluxos preestabelecidos, envolvendo várias pessoas, mas ocorre na execução do serviço através do processamento eletrônico de informações" (DOURADO, 1998, p. 82).

Para a racionalização do trabalho, é fundamental que a empresa disponha de processos apoiados por TIC sofisticadas e de fácil manuseio, não somente para coletar e armazenar dados, mas, principalmente, para tornar possível a sua integração aos processos decisórios. Com isso, há uma tendência de incorporar, nos sistemas, as informações que, antes, ficavam sob a órbita do Serviço Social, para que possam ser veiculadas, colocando em questão o sigilo profissional e o monopólio da informação que os profissionais detinham. É comum o Serviço Social manter, por exemplo, um cadastro dos atendimentos, restrito ao próprio setor, no qual os profissionais registram a sua evolução. Com a integração das informações da área de RH há uma tendência de incorporação 
dessas informações nos sistemas, absorvendo o histórico dos atendimentos num fluxo de alimentação contínuo e acessível a outros profissionais e gerências.

Destaca-se, ainda, a ampliação do acesso às informações pelos trabalhadores. Se antes o trabalhador procurava sua chefia ou o Serviço Social para obter informações sobre as políticas de RH, agora ele tem acesso a elas através da digitação de uma senha no computador. Assim, a disseminação das informações, através das TIC, pode representar, por um lado, uma perda de espaço profissional no repasse de informações e, por outro, um ganho para o trabalhador, que passa a depender menos de suas gerências e de outros profissionais para obtê-las.

Embora as informações estejam difundidas nas redes, sua socialização não rompeu as relações de poder, que permeiam as corporações, pois aquelas de conteúdo estratégico continuam centralizadas e seu acesso permanece restrito. O objeto da desconcentração são as informações operacionais, frente às quais os trabalhadores apenas decidem sobre a melhor forma de usá-las para melhorar a sua performance, da sua equipe e da empresa. Logo, as tendências de democratização das informações possibilitadas pelas TIC "tendem a colidir com as travas da direção estratégica, que não pretende dividir a sua visão de conjunto da política empresarial, especialmente em matéria de recursos humanos" (LOJKINE, 1995, p. 169).

As travas no acesso às informações ficam nítidas no monitoramento do ambiente organizacional que, em alguns casos, conta com a participação do assistente social. Este monitoramento ocorre com a realização de uma pesquisa online aplicada através de ferramentas eletrônicas que agilizam a coleta, tabulação e divulgação dos resultados. Entretanto, os trabalhadores que respondem a pesquisa não têm acesso direto aos dados coletados, pois somente os responsáveis pelo monitoramento possuem acesso aos resultados da apuração feita e, mesmo assim, "estas pessoas têm sua ação limitada no sistema de tabulação, pelos chamados filtros de confidencialidade" (BARROS; COSTA; GONZAGA; 2015, p. 125-126).

A segunda modificação, relativa à introdução da racionalidade técnica pautada no binômio eficácia/ eficiência, ocorre com a ampliação das TIC e das inovações organizacionais, promovendo a racionalização do trabalho do Serviço Social. O profissional tem que desenvolver uma capacidade lógico-abstrata, para decodificar, programar e gerenciar seu trabalho, pois, assim, será capaz de assimilar as contínuas e rápidas mudanças a que está sujeito e contribuir para o processo de melhoria contínua, otimizando seu próprio trabalho. Suas atividades são descritas e padronizadas, as ações prioritárias são identificadas e itens de controle e metas de melhoria para cada ação são estabelecidos, em conformidade com as necessidades dos clientes e da empresa. Busca-se eliminar desperdício, inconsistência e insuficiência, reduzir tempos subutilizados e introduzir esquemas de aferição do desempenho do assistente social, que também se vê premido a apresentar o resultado prático-operativo do seu trabalho.

O Serviço Social é considerado um suporte às operações da empresa, atendendo, prioritariamente, aos seus empregados. Para se adequar aos padrões de "excelência" exigidos, precisa rever seus objetivos, sua missão dentro da organização e suas principais competências. Requer também a identificação de pontos terminais da empresa: entradas, saídas, clientes, fornecedores e eventos catalisadores e, a partir dessa visão sistêmica, é possível avaliar sua eficiência e eficácia. A eficiência considera a melhor utilização dos recursos, a produtividade, a qualidade e o tempo dispensado, com base na quantidade de erros, repetições e retrabalho. A eficácia leva em conta como o serviço atende ao cliente e obtém a sua satisfação. Soma-se, ainda, a adaptabilidade e flexibilidade em lidar com as mudanças nas expectativas dos clientes e a velocidade com que são dadas soluções aos problemas por eles apresentados.

As medidas usadas para auferir o desempenho de um serviço permitem que sejam avaliados os requisitos técnicos e comportamentais da equipe de trabalho e de cada profissional. Essas medidas são processadas pelas TIC através, por exemplo, do registro de reclamações, da aplicação de enquetes de opinião sobre o atendimento prestado, de sistemas de agendamento com mensuração de dados quantitativos, inclusive, de tempo de espera, atendimento e resposta, dentre outros recursos, que geram relatórios estatísticos e analíticos para as gerências. Constata-se, portanto, uma crescente utilização de tecnologias específicas, capazes de selecionar e analisar as informações dos clientes, traduzindo-as em requisitos e indicadores de desempenho.

A pesquisa de ambiência organizacional, já citada, ocorre por meio de ferramentas eletrônicas capazes de consolidar dados e apontar as insuficiências das gerências nas relações de trabalho, que prejudicam o comprometimento dos trabalhadores com as metas. A partir das respostas dos empregados, são identificadas as debilidades de cada área e estabelecidos planos de ação que, ao invés de ficarem engavetados, são executados 
e monitorados. Sendo assim, "no formato eletrônico, o Plano de Ação fica disponível a todos, na intranet, para consulta, acompanhamento e cobrança de realização" (BARROS; COSTA; GONZAGA; 2015, p. 130).

Os sistemas de avaliação de desempenho, portanto, são condizentes com as inovações tecnológicas e organizacionais e estão, cada vez mais, atrelados às metas individuais e/ou grupais e integrados ao planejamento estratégico da empresa. Com a introdução do trabalho em equipes, como prática sistemática nas empresas, é necessário estabelecer mecanismos para direcionar as atividades e otimizar o desempenho. As metas representam tais mecanismos e os indicadores de desempenho, a elas vinculados, traduzem a qualidade e a produtividade, sendo seu controle realizado através dos dispositivos informacionais-digitais.

As metas do trabalho profissional são definidas em função daquelas previstas no âmbito gerencial e da sua contribuição para os resultados daquela equipe/gerência em maior integração a outros setores. As metas são auditadas e o cumprimento do planejamento é verificado. Essa auditoria é mediada pelo sistema integrado de RH e, através dele, quando previstos, são concedidos aumentos salariais por mérito, promoções, premiações, participação nos lucros etc. O sistema emite relatórios para monitorar a performance, considerando as metas definidas, o prazo e as etapas para seu cumprimento. Cada área tem suas medidas de desempenho verificadas através dos sistemas informatizados e, caso as políticas de gestão comportem, os possíveis ganhos para os trabalhadores são vinculados aos resultados atingidos.

As TIC associadas à nova racionalidade administrativa, portanto, permitem à empresa imprimir maior controle sobre a força de trabalho, conjugando mecanismos coercitivos e persuasivos. A coerção ocorre através das pressões exercidas sobre o desempenho no trabalho, cujas expectativas não correspondidas prejudicam o profissional podendo, inclusive, levar à sua demissão. A persuasão é estabelecida pelas estratégias de reconhecimento e recompensa, valorizando o desempenho, as competências e o comprometimento com as metas.

\section{As tecnologias da informação e comunicação, o perfil e as condições de trabalho}

As mudanças processadas na produção e nos processos de trabalho, com a introdução de inovações tecnológicas e organizacionais, redimensionaram o uso da informação e definiram novos padrões de eficácia e eficiência para o assistente social. Consequentemente, novas requisições foram postas para a sua qualificação, inflexionando as habilidades necessárias ao exercício das funções sociais e técnicas que lhe são exigidas pelas empresas. Nessa órbita, se destacam as alterações no perfil sociotécnico e nas condições de trabalho.

Com a adoção das TIC, os profissionais têm que se aculturar tecnologicamente, desenvolvendo competências, que exigem não só novos conhecimentos, mas, também, a capacidade de articular a dimensão cognitiva desses saberes com as atitudes necessárias para solucionar problemas, isto é, um conjunto de requisitos técnicos e comportamentais.

O perfil profissional condizente com os padrões de qualidade e produtividade requer a capacidade de: produzir e manipular informações, cujo processo de controle, transferência e disseminação é mediado com o auxílio das TIC; dominar linguagens codificadas e simbólicas de programas e software; manusear equipamentos e ferramentas digitais, com raciocínio lógico e pensamento sistêmico; elaborar respostas rápidas para uma ampla variedade de problemas com dinamismo; ser polivalente e exercer múltiplas funções com versatilidade frente às mudanças; gerenciar e racionalizar seu próprio trabalho, reduzindo porosidades, tempos ociosos e definindo itens de melhoria para a mensuração dos resultados; trabalhar em equipes, desenvolvendo a comunicabilidade e a interdependência com outros profissionais; exercer o controle mútuo, com base na cooperação, participação e comprometimento com metas.

Para a conformação desse perfil, os profissionais passam por programas de treinamento que promovem a qualificação e requalificação dos trabalhadores, com base na polivalência e multifuncionalidade. Se, por um lado, a qualificação, pautada na flexibilidade funcional, pode implicar novas atribuições para o assistente social, com enriquecimento do conteúdo de seu trabalho; por outro, pode representar um empobrecimento, se lhe forem repassadas tarefas terminais que não exigem capacitação e impõem responsabilidades limitadas.

Em geral, a polivalência descaracteriza as funções, tarefas e responsabilidades do assistente social, produzindo uma modificação do cargo, da remuneração e subordinação hierárquica. A exigência de um perfil flexível leva os assistentes sociais a acumularem outras funções ou absorverem atividades distintas da sua formação profissional. Além disso, as pressões exercidas sobre o desempenho para o alcance das metas 
produzem uma hipertrofia da esfera instrumental-operativa da ação profissional, em detrimento da dimensão teórico-crítica. Sendo assim, a qualificação promovida pela empresa pode configurar uma desqualificação e/ ou especialização do trabalho, com maior racionalização, padronização e/ou rotinização.

Como já assinalado, as mudanças implementadas nas empresas, principalmente com a ampliação do uso das TIC, provocam mudanças não só no perfil sociotécnico do assistente social, mas, também, nas suas condições de trabalho. Dentre essas mudanças, sobressaem a intensificação do trabalho e a redução dos postos de trabalho.

A introdução das TIC no trabalho do assistente social, sem dúvida, possibilita uma melhoria do seu fluxo, tendo em vista que há um repasse de informações e uma comunicação mais direta e imediata, que simplifica a realização de determinadas atividades e facilita a busca de soluções para os problemas apresentados, enfim, que agiliza o trabalho, tornando-o mais rápido. Porém, se, por um lado, os programas e máquinas inteligentes viabilizam a circulação veloz da informação, somando um ganho de tempo e uma subtração de atividades, as pressões subjacentes a esses processos produzem uma maior intensificação do ritmo de trabalho.

Um indicador dessa intensificação reside na capacidade de transmissão de dados e mensagens das TIC, mesmo quando o profissional está distante ou ausente do seu posto de trabalho. O fato de a máquina "secretariar" o profissional, gera maior sobrecarga de trabalho, pois há um acúmulo de tarefas pendentes para posterior execução. Somam-se a isso, as estratégias de home office e teletrabalho, que tornam mais tênues os limites que separam os tempos de trabalho e de vida, já que o trabalhador pode acessar os sistemas da empresa por computador ou telefone móvel em locais e em horários que, a rigor, seriam de "não-trabalho".

Outro aspecto da intensificação é o trabalho em equipes, pois há a exigência de que os integrantes tenham domínio e conhecimento das tarefas de todo o grupo, de modo a facilitar a adaptação às mudanças e às necessidades de remanejamento. Há também um maior controle que é exercido reciprocamente entre os membros da equipe, devido à interdependência de responsabilidades e que pode, ainda, gerar sobrecarga de trabalho, pois o profissional tem o seu tempo intensivamente ocupado, participando de várias comissões, comitês, círculos, times etc.

A intensificação do trabalho, se expressa, também, no aumento dos atendimentos feitos pelo assistente social e na amplitude e variedade das situações sobre as quais tem que intervir. Muitas vezes, o raio de ação do trabalho é ampliado, abarcando o atendimento às filiais da empresa situadas longe do local em que o profissional está lotado. Para sanar este limite, com o apoio das TIC, surge a figura do consultor de RH que, ao atuar à distância, constitui uma estratégia de enxugamento dos quadros, de otimização do trabalho e aumento do sobretrabalho.

Nas empresas, a intensificação do trabalho ocorre, sobretudo, pela aceleração do ritmo e extensão do tempo. Os profissionais trabalham além do horário da jornada de trabalho, pois há excesso de atividades e uma cobrança maior das gerências por um esforço extra. Em geral, os assistentes sociais têm seu salário achatado, mesmo com o aumento de tarefas e a diminuição do número de profissionais para realizá-las. Nessas precárias condições, procuram se adequar, reconhecendo que há vínculos empregatícios mais aviltantes no mercado de trabalho.

A redução de postos de trabalho também está associada às inovações tecnológicas e organizacionais usadas na racionalização do processo de trabalho. Esta redução vem acompanhada da terceirização e de novas modalidades de subcontratação. Com isso, há a precarização dos vínculos e das condições de trabalho e a elevação do desemprego sem perspectiva de recomposição do mercado formal. Portanto, "as escolhas gerenciais em matéria de organização do trabalho (o modo de racionalização, o nível e as modalidades de automação e de informatização) têm um impacto sobre o nível de emprego" (LINHART, 2007, p. 14).

Com relação ao assistente social, a redução dos postos de trabalho pode implicar a sua demissão sem substituição, a absorção de suas tarefas por outros trabalhadores ditos polivalentes e/ou a transferência das suas atividades para terceiros, sob a forma de consultoria. Pode também ocorrer a subcontratação, através de vínculos precários ou temporários, que repercute em termos salariais e de benefícios sociais. Apenas para os profissionais contratados diretamente, podem ocorrer melhorias salariais, como também maior dependência dos benefícios oferecidos pela empresa. Para os subcontratados, os salários são mais baixos e não contam com os mesmos benefícios, ficando sua proteção ao encargo das políticas públicas.

Deste modo, o assistente social está, por um lado, cada vez mais suscetível à maiores requisições e pressões sobre o seu desempenho profissional e, por outro, se encontra em piores condições para respondê-las. Com as 
demissões, os assistentes sociais, mantidos na empresa, passam a atender uma gama enorme de problemas e, muitas vezes, não conseguem manter o padrão de qualidade exigido. Acabam priorizando atividades básicas e pontuais, se esforçam para justificar sua permanência na empresa e obter legitimidade para sua utilidade.

Seja pela redução do número de profissionais ou por sua relocalização técnica e/ou administrativa, as mudanças nas condições de trabalho afetam o reconhecimento do assistente social, transformando-se, perversamente, em objeto de julgamento da eficácia e eficiência das suas ações. O profissional, por vezes, é culpabilizado pela precariedade do trabalho, sem que se leve em conta as condições em que é realizado, potencializando o desgaste para sua saúde e a carga social, expressa "sob todas as formas de "violência simbólica'” (FREIRE, 2003, p. 41).

As TIC, inseridas na reestruturação da produção, geram, portanto, uma enorme economia de trabalho vivo, elevando a composição orgânica do capital e, por conseguinte, impactam o mercado de trabalho, aumentando o desemprego. As formas flexíveis - a rigor, precárias - de contratação acentuam as estratificações entre os trabalhadores e incrementam a informalidade, com altas taxas de extração de trabalho excedente. Enfim, a ampliação das TIC gera instabilidade, insegurança para os trabalhadores e, também, para o assistente social.

\section{Considerações Finais}

No processo de reestruturação, o uso das TIC reforça a lógica da acumulação capitalista, aprofundando as contradições nas relações sociais de produção. $\mathrm{O}$ acesso à informação e o controle de seu fluxo, conjugados à capacidade de comunicação e transmissão de dados, tornaram as TIC essenciais para organização da produção e dos processos de trabalho, porém, com efeitos nocivos para os trabalhadores, com a intensificação e precarização do trabalho.

O Serviço Social, como especialização do trabalho coletivo, se realiza no universo do assalariamento e, como todo trabalhador, o assistente social está sujeito aos novos meios de consumo e controle da força de trabalho, assim como mais dependente do empregador, no que se refere a sua reprodução material e espiritual. Logo, $\mathrm{o}$ assalariamento submete $\mathrm{o}$ assistente social às condições gerais da produção capitalista e às injunções do processo de reestruturação.

Nas empresas, o trabalho do assistente social é inflexionado pelo redimensionamento do uso da informação e pela introdução da racionalidade técnica pautada na eficácia/eficiência, que impõem novos requisitos técnicos e comportamentais. O assistente social adquire novos conhecimentos, desenvolve outras habilidades e se torna responsável pela racionalização e gerenciamento de seu trabalho, de acordo com as metas estabelecidas. O trabalho passa, então, a ser realizado, disciplinando e avaliado por intermédio de processos informacionais.

Estas mudanças permitem comprimir o tempo de trabalho, intensificando o ritmo e impondo pressões mais rígidas ao desempenho do assistente social. Agora este tem que tomar decisões rápidas e criativas, ser polivalente e multifuncional, trabalhar em equipes, apresentar resultados, buscar a qualidade, e usar o potencial intelectual e cognitivo no manuseio das TIC.

As requisições e o conteúdo do trabalho profissional, deste modo, são perpassados pelo aumento do controle e da subordinação, atingindo, também, as condições objetivas e subjetivas de sua realização. A intensificação do trabalho e a redução dos postos alavancam a precarização dessas condições no interior das empresas. Além disso, o desemprego e a precariedade dos vínculos, contratos e relações de trabalho, acentuam a instabilidade e a insegurança para os trabalhadores, de modo geral, afetando suas formas de representação e luta.

Apesar dos paradoxos inerentes ao processo de reestruturação e inovação tecnológica das empresas, é no movimento contraditório de sua constituição que o Serviço Social pode se apropriar criticamente de suas determinações, problematizá-las e levantar alternativas voltadas às necessidades dos trabalhadores, fortalecendo os seus interesses de classe. É imperativo, portanto, que o assistente social, como profissional e trabalhador, reflita e redirecione os rumos de seu exercício profissional e, consequentemente, os resultados gerados a partir dele. 


\section{Referências}

AMARAL, A. S.; CESAR, M. J. O trabalho do assistente social nas empresas capitalistas. In: CFESS /ABEPSS. (Org.). Serviço Social: direitos sociais e competências profissionais. Brasília: CEFESS/ABEPSS, 2009.

AMARAL, A. S.; CESAR, M. J. Do feitiço da ajuda à fábrica de consensos (posfácio). In: MOTA, A. E. O feitiço da ajuda: as determinações do serviço social na empresa. 5. ed. ampl. São Paulo: Cortez, 2008.

ANTUNES, R. Os exercícios da subjetividade: as reificações inocentes e as reificações estranhadas. Cad. CRH, Salvador, v. 24, n. especial, p. 121-131, 2011. Disponível em: https://www.scielo.br/pdf/ccrh/v24nspe1/a09v24nspe1.pdf. Acesso em: 31 mar. 2021.

ANTUNES, R. Trabalho intermitente e uberização do trabalho no limiar da Indústria 4.0. In: (Org). Uberização, trabalho digital e indústria 4.0. São Paulo: Boitempo, 2020.

BARROS, A. R. N.; COSTA N. N.; GONZAGA, A. J. F. O assistente social e a ambiência organizacional. In: DOHER, I. (Org.) O serviço social em empresas para além da crítica: espaços de enfrentamento e atuação profissional. Rio de Janeiro: E-Papers, 2015.

CESAR, M. J. Serviço Social e reestruturação industrial: requisições, competências e condições de trabalho profissional. In: MOTA, A. E. (Org.). A nova fábrica de consensos. São Paulo: Cortez, 1998.

DOURADO, E. O. Reestruturação nos bancos e a ação do Serviço Social. In: MOTA, A. E. (Org.). A nova fábrica de consensos. São Paulo: Cortez, 1998.

FREIRE, L. M. B. O serviço social na reestruturação produtiva: espaços, programas e trabalho profissional. São Paulo: Cortez, 2003. IAMAMOTO, M. V. Renovação e conservadorismo no serviço social. São Paulo: Cortez, 1995.

LINHART, D. A desmedida do capital. São Paulo: Boitempo, 2007.

LOJKINE, J. A revolução informacional. São Paulo: Cortez, 1995.

MELO, A. I. S. C. Trabalho e saúde: um estudo entre trabalhadores de serviços de tecnologias da informação. 2007. Tese (Doutorado em Saúde Pública) - Fundação Oswaldo Cruz, Escola Nacional de Saúde Pública Sergio Arouca, Rio de Janeiro: ENSP/Fiocruz, 2007. MOTA, A. E. O feitiço da ajuda: as determinações do serviço social na empresa. 5. ed. ampl. São Paulo: Cortez, 2008.

VELOSO, R. Serviço Social, Trabalho e Tecnologia da Informação. Em Pauta: teoria social e realidade contemporânea, Rio de Janeiro, v. 9, n. 27, p. 71-90, jul. 2011. Disponível em: https://www.e-publicacoes.uerj.br/index.php/revistaempauta/article/view/2499/1933. Acesso em: 05 abr. 2021.

\section{Monica de Jesus Cesar}

E-mail mojcesar@gmail.com

Doutora em Serviço Social pela Escola de Serviço Social da Universidade Federal do Rio de Janeiro (UFRJ)

Professora Associada da Faculdade de Serviço Social da Universidade do Estado do Rio de Janeiro (UERJ)

\section{FSS/UERJ}

Endereço Rua São Francisco Xavier, 524, Bloco D, $8^{\circ}$ andar - Pavilhão João Lyra Filho Maracanã, Rio de Janeiro - RJ - Brasil

CEP: 20550-900

\section{Agradecimentos}

Não se aplica.

Agência financiadora

Não se aplica.

Contribuições das autoras

$\mathrm{O}$ artigo foi concebido, desenvolvido e revisado pela autora.
Aprovação por Comitê de Ética e consentimento para participação

Não se aplica.

Consentimento para publicação

Consentimento da autora.

Conflito de interesses

Não há conflito de interesses. 